\title{
Correction to: Prevention by Regular Exercise of Acute Sleep Deprivation-Induced Impairment of Late Phase LTP and Related Signaling Molecules in the Dentate Gyrus
}

\author{
Munder A. Zagaar ${ }^{1,2}$ - An T. Dao ${ }^{1}$ Ibrahim A. Alhaider ${ }^{3} \cdot$ Karim A. Alkadhi $^{1}$
}

Published online: 5 October 2017

(C) Springer Science+Business Media, LLC 2017

Correction to: Mol Neurobiol (2016) 53(5): 2900-2910

https://doi.org/10.1007/s12035-015-9176-4

The original version of this article unfortunately does not include the second affiliating institution of Dr. Munder A. Zagaar. "Department of Pharmacy Practice and Clinical Health Sciences, Texas Southern University, Houston, TX 77004" should have been included on the paper.

With this, the authors hereby publish the complete affiliating institutions.

The online version of the original article can be found at https://doi.org/ 10.1007/s12035-015-9176-4

Karim A. Alkadhi

kalkadhi@uh.edu

1 Departmentof Pharmacological and Pharmaceutical Sciences,

University of Houston, Houston, TX, USA

2 Department of Pharmacy Practice and Clinical Health Sciences, Texas Southern University, Houston, TX 77004, USA

3 Present address: College of Clinical Pharmacy, King Faisal University, Al-Hofuf, Kingdom of Saudi Arabia 